\title{
Tumour and tumour-like conditions of peripheral nerve origin: Ten years' experience
}

\author{
Ghosh A $\mathbf{A}^{1}$, Talwar OP ${ }^{2}$, Pradhan SV ${ }^{3}$
}

${ }^{1}$ Associate Professor, ${ }^{2}$ Professor and Head, ${ }^{3}$ Assistant Professor, Department of Pathology, Manipal College of Medical Sciences, Pokhara, Nepal

\begin{abstract}
Background: There are four major lesions which may arise in the peripheral nerve, namely neuroma, schwannoma, neurofibroma and malignant peripheral nerve sheath tumor.

Objective: In the present study we look into the spectrum of peripheral neural tumors including their age distribution site distribution and histopathology.

Materials and methods: This is retrospective study conducted in the Dept of Pathology, Manipal Teaching Hospital, Pokhara. All histopathologically diagnosed cases of primary lesions of peripheral nerve during the period Jan 2000 to Nov 2009 were reviewed and the data were analysed.

Result: A total of 114 cases of peripheral neural lesions were reported in the same period. Total number of nonmalignant cases was $106(93 \%)$ while malignant cases were $8(7 \%)$. Among the nonmalignant cases neurofiboma was the commonest ( 51 cases, $45 \%$ of all) closely followed by schwannoma (39 cases, 34\% of all). Among the neurofibroma cases only 2 cases had multiple neurofibromatosis while others were solitary. Among the schwannoma cases 4 were diagnosed as ancient schwannoma with presence of bizarre cells with hyperchromatic nuclei. The commonest site involved for both schwannoma and neurofibroma was scalp-face-neck followed by back. The age range for schwannoma was 16 to 75 years whereas the same for the neurofibroma cases was 2 to 82 years. MPNST cases were seen in the age range of 40 to 72 with 3 cases in upper extremity, 3 in lower extremity and 1 each in lip and cheek. 1 case was diagnosed as cellular neurofibroma with atypia in tongue and was confirmed by S100.

Conclusion The majority of the tumor are benign and the commonest benign tumor was neurofibroma of sporadic type, closely followed by schwannoma. In our study the commonest site was scalp-face-neck unlike other studies. This may be due to more compliance of the patients due to cosmetic reason.
\end{abstract}

Key words : Malignant peripheral nerve sheath tumor, Neurofibroma, Peripheral nerve, Schwannoma,

$T^{1}$ here are four major lesions which may arise in the peripheral nerve, namely neuroma, schwannoma (also called neurilemmoma or neurinoma), neurofibroma comprising the benign group and malignant peripheral nerve sheath tumor (MPNST) ${ }^{1}$. The WHO coined the term MPNST to replace previous heterogenous and confusing terms like "malignant schwannoma", "malignant neurilemmoma", "neurogenic sarcoma" and "neurofibrosarcoma"2. Peripheral nerve sheath tumors are rare ${ }^{1}$. Kransdorf MJ in 1995 reported 77 schwannomas which was only $0.2 \%$ of 39179 soft tissue tumors recorded by the US Armed Forces Institute ${ }^{3}$. The incidence of MPNST in general population is $0.001 \%$ and account for 5 to $10 \%$ of soft tissue sarcomas, about one fourth to one half occurring in the setting of neurofibromatosis ${ }^{4-8}$.
In the present study we look into the spectrum of peripheral neural lesions including their age distribution, site distribution and histopathology.

\section{Materials and methods}

This is retrospective study conducted in the Dept of Pathology, Manipal Teaching Hospital, Pokhara, Nepal. All histopathologically diagnosed cases of primary lesions of peripheral nerve during the period Jan 2000 to Nov 2009 were reviewed and the data were analysed.

\footnotetext{
Correspondence

Dr. OP Talwar

Professor and Head, Department of Pathology

Manipal College of Medical Sciences, Pokhara

E-mail: omitalwar@yahoo.com
} 
Results

A total of 114 cases of peripheral neural lesions were reported in the same period. Total number of nonmalignant cases were 106 (93\%) while malignant cases were $8(7 \%)$. Among the nonmalignant cases neurofiboma was the commonest (51 cases, $45 \%$ of all) closely followed by schwannoma (39 cases, 34\% of all) [Table 1]. Among the neurofibroma cases, only 4 cases were associated with Neurofibromatosis 1 - two with multiple neurofibromatosis, and another two with plexiform neurofibroma, while others (47 cases) were solitary. Among the schwannoma cases 4 were diagnosed as ancient schwannoma with presence of bizarre cells having hyperchromatic nuclei. Benign tumors are clearly more common in females whereas MPNST was more in males [Table 2]. The age range for schwannoma was 16 to 75 years whereas the same for the neurofibroma cases was 2 to 82 years [Table 3 ]. The commonest site involved for both schwannoma and neurofibroma was scalp-face-neck followed by back [Table 4]. MPNST cases were seen in the age range of 40 to 72 with 4 cases in upper extremity, 2 in lower extremity and 1 each in lip and cheek [Table 2,3]. 1 case was diagnosed as cellular neurofibroma with atypia in tongue and was confirmed by S100.

Table 1: Number and percentage of different benign and malignant PNST

\begin{tabular}{|c|c|c|}
\hline Entities & Number of case & Percentage of cases \\
\hline \multicolumn{3}{|l|}{ Benign } \\
\hline Neurofibroma (NF) & 51 & $45 \%$ \\
\hline Schwannoma & 39 & $34 \%$ \\
\hline Neurothekoma & 06 & $5 \%$ \\
\hline Neuroma & 05 & $4 \%$ \\
\hline Cellular NF with atypia & 01 & $1 \%$ \\
\hline Ganglion of Nv sheath & 02 & $2 \%$ \\
\hline Neurolipofibroma & 02 & $2 \%$ \\
\hline \multicolumn{3}{|l|}{ Malignant } \\
\hline MPNST & 08 & $7 \%$ \\
\hline Total Case & 114 & \\
\hline
\end{tabular}

Table 2: Sex distribution of different benign and malignant PNST

\begin{tabular}{|l|c|c|c|c|c|}
\hline & Neurofibroma & Schwannoma & Neurothekoma & Neuroma & MPNST \\
\hline Male & 22 & 13 & 3 & 4 & 6 \\
\hline Female & 29 & 26 & 3 & 1 & 2 \\
\hline Total & $\mathbf{5 1}$ & $\mathbf{3 9}$ & $\mathbf{0 6}$ & $\mathbf{0 5}$ & $\mathbf{0 8}$ \\
\hline
\end{tabular}

Table 3: Age distribution of different benign and malignant PNST

\begin{tabular}{|l|c|}
\hline Entities & Age distribution (years) \\
\hline Neurofibroma (NF) & Range 2 - 82, Median 38 \\
\hline Schwannoma & Range 16 - 75, Median 45 \\
\hline Neurothekoma & Range 16 - 40, Median 23 \\
\hline Neuroma & Range 21 - 66, Median 35 \\
\hline Cellular NF with atypia & $49 \& 44$ \\
\hline Ganglion of Nerve sheath & 2 \& 15 \\
\hline Neurolipofibroma & Range 40 - 72, Median 62 \\
\hline MPNST & \\
\hline
\end{tabular}


Table 4: Site distribution of different benign and malignant PNST

\begin{tabular}{|l|c|c|c|c|c|}
\hline SITE & Neurofibroma & Schwannoma & Neurothekoma & Neuroma & MPNST \\
\hline Head Neck Face & 20 & 9 & - & - & 2 \\
\hline Back & 8 & 8 & - & - & - \\
\hline Chest & 6 & 5 & 1 & - & - \\
\hline Abdominal wall & 2 & - & - & - & - \\
\hline Upper extremities & 6 & 6 & 3 & 4 & 3 \\
\hline Lower extremities & 6 & 6 & 2 & 1 & 3 \\
\hline Others & $\begin{array}{c}\text { Omental 1 } \\
\text { Cervix 2 }\end{array}$ & $\begin{array}{c}\text { Omental 1 } \\
\text { Larynx 1 } \\
\text { Pharynx 2 } \\
\text { Cervix 2 }\end{array}$ & - & - & - \\
\hline Total & $\mathbf{5 1}$ & $\mathbf{3 9}$ & $\mathbf{0 6}$ & $\mathbf{0 5}$ & $\mathbf{0 8}$ \\
\hline
\end{tabular}

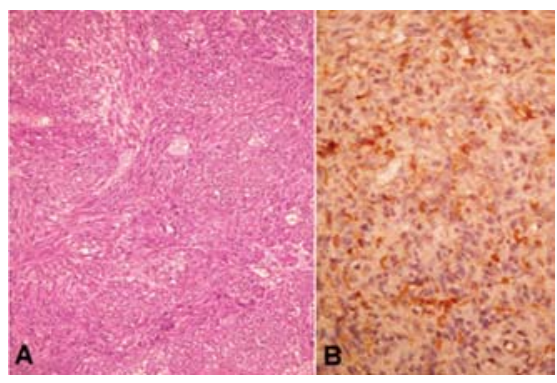

Fig 1: Neurofibroma, H/E, 50x. Inset shows cells with wavy nuclei and pointed ends, H/E, 100x

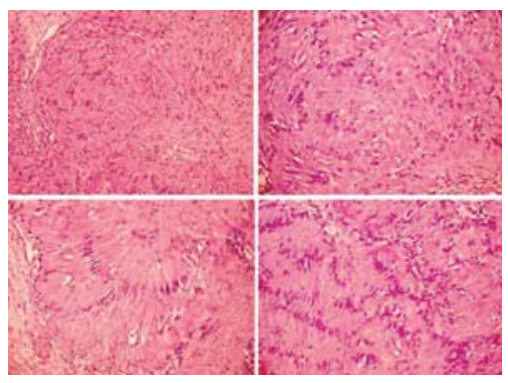

Fig 2: Schwannoma with Verocay bodies of different shape and form. H/E, 100x

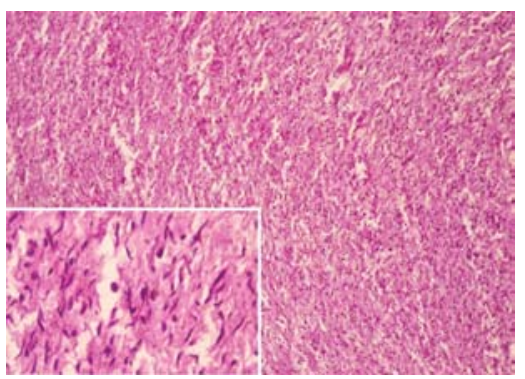

Fig 3: A. MPNST showing sweeping fascicle of spindle cells bundle. $\mathrm{H} / \mathrm{E}, 50 \mathrm{x}$.

B. S100 shows positivity
Discussion

The causes of benign and malignant PNSTs remain unknown ${ }^{1}$. The schwann cell is thought to be the major contributor to the formation of benign as well as malignant neoplasm of the nerve sheath ${ }^{2}$. Though this fact is essentially true, the exact identification of the cell of origin of the MPNST has not yet been conclusively identified $^{2}$. In patients with neurofibromatosis 1 (NF1), an autosomal dominant disorder with NF1 gene mutation and neurocutanoeous involvement, there is a $15 \%$ risk of malignant degeneration ${ }^{1}$. According to some authors, previous trauma may trigger the formation of neurofibroma and schwannoma ${ }^{9,10}$.

In one of the largest study of peripheral nerve sheath tumor, Kim DH et al in 1995 analyzed 397 cases over a span of 30 years, and found $91 \%$ to be benign tumor ${ }^{1}$. In the present study, 93\% of all cases are benign and $7 \%$ are MPNST. In the above study, the commonest (66\%) tumor was neurofibroma and among the neurofibromas $59 \%$ were solitary neurofibromas and $41 \%$ were NF1 associated neurofibromas, the next commonest benign PNST being schwannoma $(34 \% \text { of all cases })^{1}$. In the present study the commonest tumor is neurofibroma $(45 \%)$ and the second most commonest tumor is schwannoma (34\%). Unlike the 1995 study, we had only 4 cases of NF1 associated neurofiboma. However there is obvious difficulty in excluding the diagnosis of NF1 in young patients without any family history and presenting with solitary neurofibroma, as also noted by other authors ${ }^{11}$.

Solitary neurofibromas present as a superficial painless nodule affecting young people, mostly of 20-30 years and affects both genders equally ${ }^{11}$. In the present study, the age range was 2 to 82 years and females are more affected than males similarly as in the study of Furniss $\mathrm{D}$ et al ${ }^{12}$. The commonest site in our study is head neck face area but in the studies by Furniss D et al and by $\mathrm{Kim} \mathrm{DH}$ et al the commonest site were upper limb and brachial plexus region respectively ${ }^{12,1}$.

Histologically the most characteristic form shows interlacing bundles of elongated cells with wavy nuclei intimately associated with wire like strands of collagen 
that have been described as "shredded carrots"1,11 (Fig 1). However the histopathology may vary and it may be with high cellularity, high amount of myxoid material, epithelioid change of schwann cell ${ }^{11}$. In our study we have seen 3 cases with extensive myxoid change, 2 case with cystic change and 1 case of diffuse NF. Diffuse NF is an uncommon distinct entity, commonly seen in head and neck region of children as a plaque like elevation.

We had 4 cases of NF1 in total, 2 of them showed plexiform neurofibroma (PN) which is pathognomonic of the disease ${ }^{11}$. PN always develop in early childhood and microscopically shows a tortuous mass of expanded nerves which are seen cut in various planes of sections.

Schwannomas occur at all ages, most commonly between 20 and 50 years and they affect genders equally ${ }^{11}$. However, in the present study, females are more commonly affected in a ratio of 2:1 and the age range affected are 16 to 75 years. In the study by Furniss $D$ et al, the males are almost twice affected than female ${ }^{12}$ The commonest sites affected are usually head and neck region followed by upper and lower extremities ${ }^{11}$. In our study the commonest site being trunk followed by head and neck area. In the study by Furniss D et al the commonest site was upper limb and in the study by $\mathrm{Kim} \mathrm{DH}$ et al, the commonest site was brachial plexus region ${ }^{1,12}$. Microscopically they typically show hypercelllaur Antoni A areas with Verocay bodies and hypocellular Antoni B areas (Fig 2). We reported 4 cases of ancient schwannomas which are schwannomas with degenerative changes such as marked nuclear atypia, cyst formation, calcification, hemorrhage and hyalinization. Though the nuclear atypia may be marked and worrisome but mitotic figures are not seen. They behave as ordinary schwannomas ${ }^{11,13,14}$.

In our study, MPNST cases were seen in the age range of 40 to 72 with 3 cases in upper extremity, 3 in lower extremity and 1 each in lip and cheek. In the studies by Furniss D et al (31 cases) and Kim DH et al (36 cases), the commonest site of MPNST were lower limb (16 cases) and brachial plexus (21 cases) respectively ${ }^{1,12}$. The age range is usually 20 to 50 years, in our study the range is 40 to 72 years $^{6}$. The size is known to be usually more than $5 \mathrm{cms}^{15}$. In our study the size ranged from 2 $\mathrm{cms}$ to $12 \mathrm{cms}$, with 2 cases between 2 to $5 \mathrm{cms}$.

Most MPNST are known to arise from major nerve trunks of proximal part of extremities and only a few arise in head face and neck area ${ }^{15}$. However in our study we have 2 out of 7 cases arising in oral cavity. However the sample size is small for any comment. In other studies the common sites are lower extremities and brachial plexus area followed by trunk $k^{1,12}$
The clinical features suggestive of malignancy are similar to those of soft tissue sarcoma in general - i.e., large size, pain, increase in size, and location deep to deep fascia ${ }^{1}$.

MPNST may show differentiation towards schwann cell, perineural cell and fibroblasts. However, microscopically, most MPNST resemble fibrosarcomas in their overall organization with certain modifications ${ }^{15}$ (Fig 3). The cells are mostly spindle or fusiform with indistinct lightly stained cytoplasm and wavy, buckled or comma shaped nuclei. Different patterns include sweeping fascicles, alternate hyper and hypocellular areas, nodular areas and presence of myxoid zones ${ }^{15}$.

The major differentials include fibrosarcoma, monophasic synovial sarcoma and leiomyosarcoma. The former two entities have more uniform fascicular pattern. Synovial sarcoma often shows rudimentary epithelial differentiation. Leiomyosarcoma classically shows centrally placed blunt ended nuclei and juxtanuclear vacuoles. And obviously, none of them show features of neural differentiation seen in MPNST ${ }^{15}$.

\section{Conclusion}

The majority of the tumor arising in peripheral nerve are benign and the commonest benign tumor was neurofibroma of sporadic type, closely followed by schwannoma. In our study the commonest site was scalp-face-neck unlike other studies. This may be due to more compliance of the patients due to cosmetic reason. We found much less percentage of NF1 cases compared to other studies, further studies from this region are required to shed light on this issue.

\section{References}

1. Kim DH, Murovic JA, Tiel RL, Moes G, Kline DG. A series of 397 peripheral neural sheath tumors: 30-year experience at Louisiana State University Health Sciences Center. J Neurosurg. 2005;102(2):246-55.

2. Gupta G, Maniker A. Malignant peripheral nerve sheath tumors Review. Neurosurg Focus. 2007;22(6):E12.

3. Kransdorf MJ. Benign soft-tissue tumors in a large referral population: distribution of specific diagnoses by age, sex, and location. AJR. 1995;164:395-402.

4. Baehring JM, Betensky RA, Batchelor TT. Malignant peripheral nerve sheath tumor: the clinical spectrum and outcome of treatment. Neurology. 2003;61:696-8.

5. Stark AM, Buhl R, Hugo HH, Mehdorn HM. Malignant peripheral nerve sheath tumours- 
report of 8 cases and review of the literature. Acta Neurochir. 2001;143:357-64.

6. Ducatman BS, Scheithauer BW, Piepgras DG, Reiman HM, Ilstrup DM. Malignant peripheral nerve sheath tumors. A clinicopathologic study of 120 cases. Cancer. 1986;57(10):2006-21.

7. Hruban RH, Shiu MH, Senie RT, Woodruff JM. Malignant peripheral nerve sheath tumors of the buttock and lower extremity. A study of 43 cases. Cancer. 1990;66(6):1253-65.

8. Wong WW, Hirose T, Scheithauer BW, Schild SE, Gunderson LL. Malignant peripheral nerve sheath tumor: Analysis of treatment outcome. Int. J. Radiat Oncol Biol Phys. 1998; 42(2): 351-60

9. Cheng YS, Binnie W, Shroyer J, Bridges G: A forehead mass present for 53 years after trauma in childhood. J Oral Pathol Med. 2003; 32: 61217.

10. Wilkinson JM, McClelland MR, Battersby RD: Spinal cord schwannoma after vertebral trauma: a causal relation? J Neurol Neurosurg Psychiatry. 1995; 59(4):358.

11. Sharon W Weiss, John R Goldblum, editors. Enzinger and Weiss's Soft Tissue Tumors. 5 th ed. Philadelphia: Mosby; 2008. P.825-902.

12. Furniss D, Swan MC, Morritt DG, Lim J, Khanna T, Way BL, et al. A 10-year review of benign and malignant peripheral nerve sheath tumors in a single center: clinical and radiographic features can help to differentiate benign from malignant lesions. Plast Reconstr Surg. 2008;121(2):529-33.

13. Ackerman LV, Taylor FH. Neurogenic tumors within the thorax. Cancer. 1951;4:669 - 91

14. Dahl I. Ancient neurilemmoma (schwannoma). Acta Pathol Microbiol Scand. 1977;85(6):8128.

15. Sharon W Weiss, John R Goldblum, editors. Enzinger and Weiss's Soft Tissue Tumors. 5 th ed. Philadelphia: Mosby; 2008. P.903-944. 